\title{
Study of the propagation of combustion products on the models of road tunnels for various fire scenarios
}

\author{
Omar Lanchava
}

\author{
G. Tsulukidze Mining Institute, Tbilisi, Mindeli Street, 7 \\ lanchava@mining.org.ge
}

The idea of the research is based on increasing the aerodynamic resistance of the tunnel with the help of a transformable system (TS), which will prevent the spread of combustion products without interfering with people's movement, and will stimulate the differentiation of fresh and polluted air flows. As a result, in the critical sections of the tunnel, fresh air maintains longer, giving more time for evacuation. The noted event is characterized by a sharply limited time interval, which depends on many components, including the power of the fire and the scenario of its development, the type of toxic compounds emitted and the nature of their propagation, the geometry of the tunnel and the ventilation system. At the beginning of the 21th century, in newly built tunnels began to build fireproof barriers that can divide the tunnel into short sections. These barriers prevent the spread of fire, smoke and other combustion products along the length of the tunnels. But this method is not the final decision, due to the fact that there is no place for its implementation in the "old" tunnels without sacrificing the underground space of the tunnel and its traffic capacity. It should be emphasized that the use of the method of dividing the tunnel into short sections is not envisaged in the design solutions in the tunnels being operated and under construction in Georgia. Particularly in Georgia it is planned to build more than 50 road tunnels in the next 3-5 years. Inspecting the design decisions of these tunnels revealed that the only significant risk factor for them is the fire when safety measures do not provide for the operational separation of them. Based on this the issue of the development of this project is directly vital and very relevant for the conditions in Georgia. There are required theoretical analysis the correlation of critical speed and backlayering length with fire characteristics without the influence of the transformable system and taking into account its influence. Accordingly, the influence of artificial barriers on the dynamics of ventilation flows, the formation and development of bifurcation flows, the propagation of damaging factors and other important parameters should be determined, which should be applicable to the geometry, topology and location of a particular tunnel.

Acknowledgement. This work was supported by Shota Rustaveli National Science Foundation (SRNSF) [Grant number AR-19-1936, Project title "Development and testing of transformable system to save life in road tunnel in case of fire"].

\section{References}

1. Li Y.Z., Ingason H. Discussions on critical velocity and critical Froude number for smoke control in tunnels with longitudinal ventilation. Fire Safety Journal, Vol. 99, 2018.

2. Lanchava O., Medzmariashvili E., Ilias N., Khitalishvili G., Lebanidze Z. Prospects of usage of transformable systems for extinguishing fire in tunnels. International Scientific Conference "Advanced Lightweight Structures and Reflector Antennas", Tbilisi, 2009.

3. Lanchava O., Ilias N., Nozadze G. Some problems for assessment of fire in road tunnels. Quality Access to Success, Vol. 18, S1, 2017. 